\title{
Produtividade de rúcula hidropônica cultivada em diferentes épocas e vazões de solução nutritiva
}

\author{
Gláucio da C Genuncio; Renata Aparecida C Silva; Núbia M e Sá; Wellington Mary; Everaldo Zonta \\ UFRRJ-Dep ${ }^{\text {to }}$ Solos, Instituto de Agronomia, Rod. BR 465 km 7, 23890-000 Seropédica-RJ; glauciogenuncio@gmail.com; \\ renatacosta@yahoo.com.br; nubia_mai@yahoo.com.br; wmary@ufrrj.br; ezonta@ufrrj.br
}

\section{RESUMO}

A rúcula é uma das principais hortaliças produzidas no Brasil via hidroponia. Entretanto, além da aplicação de uma solução nutritiva adequada à cultura, torna-se imprescindível o conhecimento e o controle das variáveis intrínsecas ao manejo da solução nutritiva. Assim, o objetivo foi avaliar o acúmulo de biomassa fresca de parte aérea e raiz e a produtividade da rúcula cultivada em três vazões de solução nutritiva em hidroponia NFT, durante seis ciclos de cultivo. Os tratamentos consistiram de três vazões de solução nutritiva, sendo $\mathrm{V} 1=0,75, \mathrm{~V} 2=1,00 \mathrm{e} \mathrm{V} 3=1,50 \mathrm{~L} \mathrm{~min}^{-1}$. Foram avaliados seis ciclos de cultivo (de julho a dezembro). O delineamento experimental foi de blocos ao acaso com oito repetições. Realizaram-se as colheitas aos 30 dias após o transplante para os canais de hidroponia. O acúmulo de biomassa de parte aérea e de raiz foi maior nos meses de novembro e dezembro, devido a maiores temperaturas em casa de vegetação. Foi observado menor valor de biomassa de parte aérea na menor vazão do sistema. A produtividade da parte aérea e total (parte aérea + raiz) foi maior nos meses mais quentes. Observou-se um incremento na produtividade com um aumento da vazão da solução nutritiva nos canais de hidroponia.

Palavras-chave: Eruca sativa, cultivo sem solo, produção.

\begin{abstract}
Yield of hydroponic rocket cultivated in different seasons and flow rates of nutrient solution

The rocket is one of the main vegetable crops produced in Brazil through hydroponics. Nevertheless, besides the application of an appropriate nutrient solution for the crop, the knowledge and control of intrinsic variables for the management of the nutrient solution is essential. The accumulation of fresh biomass of the aboveground part, roots and the yield of rocket grown in three flow rates of nutrient solution during six crop cycles was studied. The treatments consisted of three flows rates of nutrient solution, $\mathrm{V} 1=0.75, \mathrm{~V} 2=1.00$ and $\mathrm{V} 3=$ $1.50 \mathrm{~L} \mathrm{~min}^{-1}$. We also evaluated six cycles of cultivation (from July to December). The experimental design was randomized blocks with eight replications. Harvest occurred 30 days after the transplanting date to the hydroponic channels. The yield of biomass of the aboveground part and of roots was higher in the months of November and December, due to the higher temperatures into the greenhouse. The lowest value of aboveground part biomass was registered in the lowest flow rate of nutrient solution. The aboveground part and total (aboveground part + root) biomass were higher in the warmer months. An increase of yield was observed with the improvement of the flow rate of nutrient solution through the channels.
\end{abstract}

Keywords: Eruca sativa, soilless cultivation, production.

(Recebido para publicação em 21 de julho de 2010; aceito em 30 de novembro de 2011) (Received on July 21, 2010; accepted on November 30, 2010)

$\mathrm{O}_{\mathrm{p}}^{\mathrm{c}}$ cultivo protegido permite ao produtor interferir nas condições ambientais controlando vento, chuva e radiação solar. Esse controle associado à hidroponia, que é uma técnica que possibilita o fornecimento de nutrientes em níveis adequados ao crescimento de culturas, minimiza perdas de produção e propicia melhor qualidade às hortaliças tanto folhosas quanto frutíferas (Furlani et al., 1999).

Para o sucesso no cultivo de hortaliças em hidroponia, além de uma solução nutritiva adequada à cultura, torna-se imprescindível o adequado manejo desta solução, por influenciar diretamente na produção e na qualidade das culturas hidropônicas. Dentre os fatores a serem manejados têm-se a concentração de oxigênio, a condutividade elétrica (CE), o $\mathrm{pH}$, a temperatura, assim como o tempo e a vazão da solução disponibilizada às raízes das plantas durante todo o seu ciclo (Furlani et al., 1999).

Valores próximos de $12 \mathrm{mg} \mathrm{L}^{-1} \mathrm{de}$ $\mathrm{O}_{2} ; 6,0$ de $\mathrm{pH}$ e $27^{\circ} \mathrm{C}$ de temperatura da solução são os parâmetros utilizados por produtores nas diversas regiões do Brasil. Por outro lado, existe uma ampla variação quanto à $\mathrm{CE}$, ao tempo e à vazão de irrigação a ser estabelecida na hidroponia. Para alface, que corresponde à cultura referência neste sistema, valores de CE podem variar de 0,9 a 2,5 $\mathrm{mS} \mathrm{cm}{ }^{-1}$ (Furlani et al., 1999; Schmidt et al., 2001; Rodrigues, 2002). Já a vazão para diversas hortaliças folhosas varia de 1,2 a 2,0 L min'-1 (Helbel Júnior et al., 2007).

A rúcula é uma das principais hortaliças folhosas produzidas no Brasil via hidroponia, por possuir ciclo curto, apresentar rico conteúdo nutricional (K, $\mathrm{S}, \mathrm{Fe}$, proteínas, vitaminas $\mathrm{A}$ e $\mathrm{C}$ ), alta produção por área e ampla aceitabilidade pelo mercado consumidor, devido às suas diferenciadas características organolépticas (Reghin et al., 2004; Amorim et al., 2007).

Em termos de acréscimos em produção, Purqueiro \& Tivelli (2007) destacam que, no período de 1997 a 2006 , a rúcula comercializada no estado de São Paulo apresentou um crescimento de $333 \%$ em oferta. Já Cavarianni et al. (2008) constataram um incremento de $78 \%$ em volume de rúcula comer- 
cializada em todo o território nacional entre 1997 a 2003. Todavia, a produção atual não atende à elevada demanda dos grandes centros consumidores, fato este que está promovendo uma expansão desta cultura em diversas partes do Brasil, principalmente na região Sudeste (Purqueiro \& Tivelli, 2007).

Sendo assim, este trabalho teve por objetivo avaliar o acúmulo de biomassa fresca de parte aérea e raiz, assim como a produtividade da rúcula hidropônica em função de vazões de solução nutritiva e épocas de plantio.

\section{MATERIAL E MÉTODOS}

Conduziram-se seis experimentos em sistema hidropônico NFT, entre julho e dezembro de 2006, no Departamento de Solos da UFRRJ, em Seropédica-RJ (22 45'32”S, 4341'50"W, 33 m de altitude). O clima local é classificado como Aw segundo Köppen \& Geiger (1928), com verão chuvoso e inverno seco. As médias das temperaturas máximas, mínimas e de umidade relativa do ar são de $25,1^{\circ} \mathrm{C}, 19,5^{\circ} \mathrm{C}$ e $79 \%$, respectivamente, com precipitação anual de $2.097 \mathrm{~mm}$ (INMET, 2009).

A casa de vegetação utilizada foi de formato tipo arco, com 4,20 m de pé-direito e $5,30 \mathrm{~m}$ de altura no vão central, coberta com filme plástico e laterais protegidas com tela antiafídica. As médias de temperaturas máximas e mínimas, assim como a umidade relativa do ar no interior da casa de vegetação foram registradas diariamente nos horários de 9:00 e 15:00 horas, com o uso de termômetros de máxima e mínima e higrômetro de leitura direta (Tabela 1).
Foi utilizada a cultivar Cultivada (Sakata Sementes). As sementes foram germinadas em câmara escura. As plântulas foram crescidas, em casa de vegetação, em bandejas de polipropileno de 200 células e fibra de coco (média de 12 plantas por célula) e nutridas com solução de Furlani et al. (1999), modificada para ferro $\left(60 \mathrm{mg} \mathrm{L}^{-1}\right.$ de FeEDDHA-6\%), diluída a $1 / 4$ até aos 12 dias após a semeadura (DAS). Aos 12 DAS, as mudas foram transplantadas para os canais de cultivo, que tinham dimensões de $3 \mathrm{~m}$ de comprimento, e espaçamentos de $0,23 \mathrm{~m}$ entre perfis e $0,15 \mathrm{~m}$ entre plantas.

A composição da solução nutritiva, pós transplante, continha as seguintes doses de fertilizantes, em $\mathrm{mg} \mathrm{L}^{-1}$ : 750 de nitrato de cálcio; 500 de nitrato de potássio; 150 de fosfato monoamônio; 400 de sulfato de magnésio; 0,15 de sulfato de cobre; 0,50 de sulfato de zinco; 1,50 de sulfato de manganês; 1,50 de ácido bórico; 0,15 de molibdato de sódio e 60 de FeEDDHA-6\%. A reposição da solução nutritiva foi realizada a partir de soluções estoque, seguindo-se recomendações de Furlani et al. (1999). Para o ajuste do pH da solução, entre 6,0 a 6,5 , aplicaram-se soluções de $0,1 \mathrm{~mol}$ $\mathrm{L}^{-1}$ de $\mathrm{KOH}$ ou $\mathrm{HCl}$.

Os tratamentos consistiram de três vazões de solução nutritivas, V1=0,75, $\mathrm{V} 2=1,00$ e $\mathrm{V} 3=1,50 \mathrm{~L} \mathrm{~min}^{-1}$. O delineamento experimental foi de blocos ao acaso com três tratamentos e oito repetições, para cada época. Cada bancada continha oito canais e cada canal 20 plantas, com dois canais por tratamento.

A circulação da solução nutritiva, no período diurno foi de 15 minutos a cada 15 minutos durante 12 horas, com início às 6 horas. No período noturno, a circulação foi de 15 minutos a cada 3 horas. A irrigação foi realizada a partir de sistemas individuais de bancada e acionados por bombas de $32 \mathrm{~W}$ de potência. $\mathrm{O}$ volume do reservatório foi de $150 \mathrm{~L}$, proporcionando uma relação de, aproximadamente, $1 \mathrm{~L} /$ planta.

Realizaram-se as colheitas aos 42 dias após a semeadura ou 30 dias após transplante para os canais hidropônicos, e foram analisadas as biomassas frescas de parte aérea e de raiz. As plantas foram colhidas entre 7:00 e 9:00 horas e de 18:00 às 20:00 horas, a fim de se evitar variações na biomassa, ocasionadas pela regulação do fluxo transpiratório. Após coleta da biomassa, foi calculada a produtividade $\left(\mathrm{kg} \mathrm{m}^{-2}\right)$. Sendo esta calculada a partir da multiplicação da biomassa da parte aérea $\left(\mathrm{g}_{\text {planta }}{ }^{-1}\right)$ pela quantidade de plantas $\mathrm{m}^{2}$ de bancada (33 plantas $/ \mathrm{m}^{2}$ ).

A análise de variância foi em blocos ao acaso, em esquema fatorial $3 \times 6$, composto por três vazões de solução nutritiva e seis épocas de colheita, com cinco blocos por tratamento e oito repetições por bloco utilizando-se o programa estatístico SAEG v. 8.0 com 5\% de probabilidade de erro. As médias do fator vazão da solução nutritiva foram comparadas pelo teste de Tukey.

\section{RESULTADOS E DISCUSSÃO}

Foram observados valores de temperaturas máximas $4,1^{\circ} \mathrm{C}$ superiores em ambiente de cultivo protegido em relação ao ambiente externo, durante a condução dos experimentos. Faria

Tabela 1. Médias mensais de temperaturas máximas e mínimas e umidade relativa do ar, registradas diariamente às 9:00 e 15:00 horas, durante o ciclo de cultivo de rúcula, de julho a dezembro de 2006, no interior e exterior da casa de vegetação (average monthly maximum and minimum temperatures and relative humidity, recorded daily at 9:00 and 15:00 hours during the crop cycle of rocket, from July to December 2006, inside and outside the greenhouse). Seropédica, UFRRJ, 2006.

\begin{tabular}{|c|c|c|c|c|c|c|c|c|c|c|}
\hline \multirow{3}{*}{ Meses } & \multicolumn{5}{|c|}{ Interno } & \multicolumn{5}{|c|}{ Externo } \\
\hline & \multicolumn{2}{|c|}{ Horário } & \multicolumn{2}{|c|}{ Temperaturas } & \multirow{2}{*}{ UR (\%) } & \multicolumn{2}{|c|}{ Horário } & \multicolumn{2}{|c|}{ Temperaturas } & \multirow{2}{*}{ UR (\%) } \\
\hline & 9:00 & 15:00 & Max & Min & & 9:00 & 15:00 & Max & Min & \\
\hline Julho & 26,9 & 34,4 & 37,1 & 18,1 & 53,6 & 25,6 & 31,6 & 34,1 & 17,9 & 57,3 \\
\hline Agosto & 26,8 & 32,1 & 35,5 & 18,7 & 61,8 & 25,8 & 28,7 & 31,4 & 18,6 & 60,7 \\
\hline Setembro & 26,5 & 29,1 & 32,1 & 19,0 & 61,7 & 25,6 & 30,1 & 31,3 & 21,8 & 63,2 \\
\hline Outubro & 28,5 & 31,8 & 32,3 & 22,0 & 62,3 & 25,8 & 31,8 & 30,1 & 21,5 & 59,0 \\
\hline Novembro & 30,1 & 29,7 & 35,0 & 20,8 & 72,8 & 27,2 & 27,9 & 31,6 & 20,1 & 71,0 \\
\hline Dezembro & 32,4 & 31,1 & 37,9 & 22,4 & 67,6 & 28,0 & 28,5 & 36,3 & 23,4 & 66,1 \\
\hline
\end{tabular}


Tabela 2. Produtividades médias de rúcula hidropônica, em diferentes vazões de solução nutritiva nos meses de julho a dezembro de 2006 (average productivity of hydroponic rocket, at different flow rates of nutrient solution from July to December 2006). Seropédica, UFRRJ, 2006.

\begin{tabular}{|c|c|c|}
\hline \multirow{2}{*}{ Meses } & \multicolumn{2}{|c|}{ Produtividade $\left(\mathrm{kg} \mathrm{m}^{-2}\right)$} \\
\hline & Parte aérea & Total \\
\hline Julho & $2,58 \mathrm{c}$ & $3,19 \mathrm{~d}$ \\
\hline Agosto & $2,67 \mathrm{c}$ & $3,31 \mathrm{~cd}$ \\
\hline Setembro & $2,78 \mathrm{c}$ & $3,48 \mathrm{~cd}$ \\
\hline Outubro & $3,21 \mathrm{bc}$ & $3,97 \mathrm{bc}$ \\
\hline Novembro & 4,38 a & 5,48 a \\
\hline Dezembro & $3,91 \quad b$ & $4,72 \mathrm{~b}$ \\
\hline Média & 3,26 & 4,03 \\
\hline Vazão (L min ${ }^{-1}$ ) & Parte aérea & Total \\
\hline 0,75 & $2,99 \mathrm{~b}$ & $3,75 \mathrm{~b}$ \\
\hline 1,00 & $3,18 \mathrm{ab}$ & $3,92 \mathrm{ab}$ \\
\hline 1,50 & 3,59 a & 4,39 a \\
\hline Média & 3,26 & 4,03 \\
\hline
\end{tabular}

*Médias seguidas pela mesma letra na coluna não diferem pelo teste de Tukey (averages followed by the same letter in columns did not differ by Tukey test). Seropédica, UFRRJ, RJ, 2006.

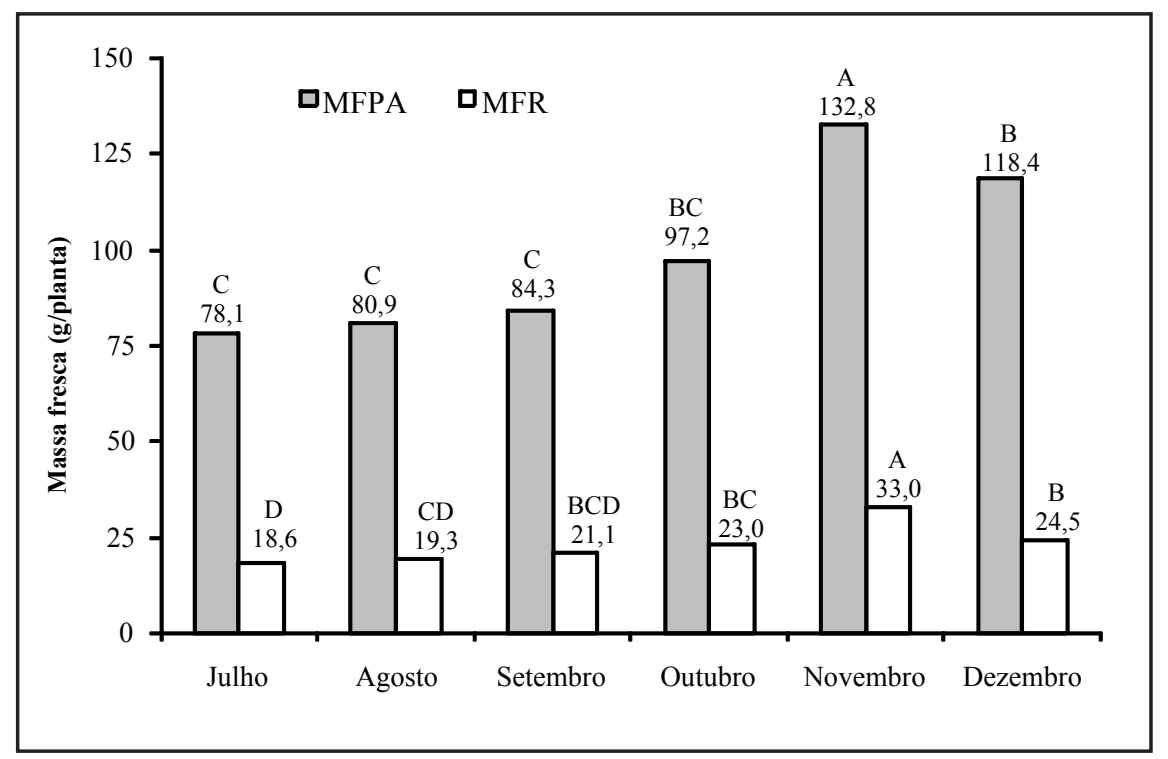

Figura 1. Massa fresca de parte aérea e raízes de rúcula cultivada em hidroponia durante seis ciclos de cultivo, nos meses de julho a dezembro de 2006 (fresh weight of aboveground part and roots of rocket grown in hydroponics during six crop cycles from July to December 2006). Seropédica, UFRRJ, 2006.

*Médias seguidas pela mesma letra não diferem pelo teste de Tukey (means followed by the same letter did not differ by Tukey test).

Junior (1997) e Pereira et al. (2004) também observaram acréscimos de temperatura em ambientes de cultivo protegido próximos aos registrados neste trabalho. Nos meses de novembro e dezembro, constataram-se aumentos de temperatura na casa de vegetação pelas maiores produções de biomassa de parte aérea observadas nestes meses (Figura 1).

Considerando a densidade de plantas em cada bancada, de 33 plantas $/ \mathrm{m}^{2}$, a produção em $\mathrm{g} /$ planta foi convertida para $\mathrm{kg} \mathrm{m}^{-2}$; sendo este um parâmetro gradativamente utilizado por produtores hidropônicos como critério de avaliação de rentabilidade da cultura. Com isso as produtividades totais observadas neste trabalho, assim como suas diferenças de acordo com as variáveis ambientais (temperatura e umidade), descritas na Tabela 2, foram próximas às observadas por Cavarianni (2004); Pereira et al. (2004); Reghin et al. (2004) e Purquerio (2005). Por outro lado, Costa et al. (2011) ao cultivarem rúcula em ambiente protegido e com temperaturas superiores a $30^{\circ} \mathrm{C}$ obtiveram produtividades próximas a $6,0 \mathrm{~kg} \mathrm{~m}^{-2}$.

Segundo Filgueira (2008), a rúcula vem demonstrando uma boa adaptação ao cultivo de verão, cujas temperaturas são mais elevadas, propiciando um incremento em produtividade até certos limites de temperaturas; em contrapartida, pode-se observar nestas situações a emissão de pendão floral, assim como folhas menores e rijas. Fato este observado pela queda de produtividade no mês de dezembro, possivelmente associado às maiores temperaturas deste período (Tabela 2). De modo geral, produtividades com variação entre 1,5 a $4,7 \mathrm{~kg} \mathrm{~m}^{-2}$ vêm sendo observadas para esta cultura (Takaoka \& Minami, 1984; Minami \& Tessarioli, 1998) aliadas tanto às características ambientais como aos tratos culturais aos quais os cultivos são submetidos.

Foram observados valores de biomassa de parte aérea, em $\mathrm{g} /$ planta de 90,$6 ; 96,5$ e 108,7 para as vazões de 0,$75 ; 1,0$ e $1,50 \mathrm{~L} / \mathrm{min}$, respectivamente. Entretanto, ao se comparar o sistema radicular das plantas crescidas nos diferentes tratamentos, pode-se constatar que estes valores não foram alterados pelas diferentes vazões do sistema $(23,1$; 22,4 e 24,3 g planta $^{-1}$ para as vazões de 0,$75 ; 1,0$ e $1,50 \mathrm{~L} \mathrm{~min}^{-1}$, respectivamente).

Supõe-se que os acréscimos de biomassa de parte aérea nas plantas submetidas às vazões de 1,0 e $1,5 \mathrm{~L} \mathrm{~min}^{-1}$ 
deveram-se à maior disponibilidade de nutrientes, ocasionado pelo fluxo de massa na região da rizosfera, e possível incremento na absorção de nutrientes e oxigênio pela rúcula, com consequente crescimento da parte aérea. $\mathrm{O}$ aumento da vazão da solução pode ter contribuído a menores temperaturas de solução nutritiva durante as horas mais quentes do dia, uma vez que há maior volume e menor tempo de exposição durante o percurso no canal havendo menor efeito da troca de calor sobre as plantas (parte aérea e raiz).

De modo geral, verificou-se que as produtividades de parte aérea e total foram maiores entre os meses de outubro a dezembro, assim como houve incremento na produção e produtividade de acordo com aumento da vazão da solução nutritiva acima de $1,0 \mathrm{~L} \mathrm{~min}^{-1}$ (Figura 1 e Tabela 2, respectivamente).

O cultivo hidropônico de rúcula além de possibilitar a produção em condições ambientais mais amenas quanto em condições de temperatura mais altas pode, ao ser manejado de forma eficiente quanto à vazão da solução, favorecer acréscimos em produtividade da cultura.

\section{AGRADECIMENTOS}

Agradecemos às empresas Hidrogood, Lumaplast, Qualifértil e
Sakata pelos materiais cedidos.

\section{REFERÊNCIAS}

AMORIM HC; HENZ GP; MATTOS LM. 2007. Identificação dos tipos de rúcula comercializados no varejo do Distrito Federal. Boletim de Pesquisa e Desenvolvimento da Embrapa Hortaliças 34: 1-13.

CAVARIANNI RL; FILHO ABC; CAZETTA JO; MAY A; CORRADI MM. 2008. Nutrient contents and production of rocket as affected by nitrogen concentrations in the nutrients solution. Scientia Agrícola 65: 652-658.

CAVARIANNI RL. 2004. Produção de cultivares de rúcula no sistema NFT e teores de nitrato. Jaboticabal: UNESP-FCA. 42p (Dissertação mestrado).

COSTA CMF; SEABRAJUNIOR S; ARRUDA GR; SOUZA SBS. 2011. Desempenho de cultivares de rúcula sob telas de sombreamento e campo aberto. Semina: Ciências Agrárias 32: 93-102.

FARIA JUNIOR, MJA. 1997. Avaliação de diferentes arquiteturas de estufas, coberturas de solo com filme plástico, em híbridos de pimentão (Capsicum annuum L.). Jaboticabal: UNESP-FCAV. 102p (Tese doutorado).

FILGUEIRA FAR. 2008. Novo manual de olericultura: agrotecnologia moderna na produção e comercialização de hortaliças. Viçosa: UFV. 421p.

FURLANI PR; SILVEIRA LCP; BOLONHESI D; FAQUIN V. 1999. Cultivo hidropônico de plantas. Campinas: IAC. 52p (Boletim Técnico 180).

HELBEL JÚNIOR C; REZENDE R; SANTOS SH; FREITAS PSL; AZEVEDO TLF FRIZZONE JA. 2007. Soluções nutritivas, vazões e qualidade de alface hidropônica. Acta Scientiarum Agronomy 29: 291-295.
I N S T I T U T O N A C I O N A L D E METEOROLOGIA. 2009, 16 de abril. Clima, gráficos climatológicos, periodo de 1961 a 1990. Disponível em http://www.inmet.gov. $\mathrm{br} / \mathrm{html} / \mathrm{clima}$.php

KÖPPEN W; GEIGER R. Klimate der Erde. 1928. Gotha: Verlag Justus Perthes. Wall-map. $150 \mathrm{~cm} \times 200 \mathrm{~cm}$.

MINAMI K; TESSARIOLI NETO J. 1998. A cultura da rúcula. Piracicaba: usp-ESALQ. $19 \mathrm{p}$.

PEREIRA ER; SILVA IJO; MOURA DJ; PIEDADE SMS. 2004. Desempenho da cultura da rúcula cultivada em época de verão em túneis baixos de polietileno perfurado. Engenharia Agrícola 24: 285-290.

PURQUEIRO LFV. 2005. Crescimento, produção e qualidade de rúcula (Eruca sativa Mill.) em função do nitrogênio e da densidade de plantio. Botucatu: UNESP-FCA. 119p (Tese doutorado).

PURQUERIO LFV; TIVELLI SW. 2007. O Mercado da rúcula. Disponível em htpp:// www.iac.sp.gov.br/Tecnologias/Rucula/ Rucula.htm

REGHIN MY; OTTO RF; VINNE, JVD. 2004. Efeito da densidade de mudas por célula e do volume da célula na produção de mudas e cultivo da rúcula. Ciência Agrotécnica 28: 287-295.

RODRIGUES LRF. 2002. Técnicas de cultivo hidropônico e de controle ambiental no manejo de pragas, doenças e nutrição vegetal em ambiente protegido. Jaboticabal: unespFunep. 762p.

SCHMIDT D; SANTOS OS; BONNECARRÉRE RA; MARIANI AO; MANFRON PA. 2001. Desempenho de soluções nutritivas e cultivares de alface em hidroponia. Horticultura Brasileira 19: 122-126.

TAKAOKA M; MINAMI K. 1984. Efeito do espaçamento entre linhas na produção de rúcula (Eruca sativa L.). O solo 76: 51-55. 